\title{
Neural network for modeling the capture of lead and cadmium ions from wastewater using date palm stones
}

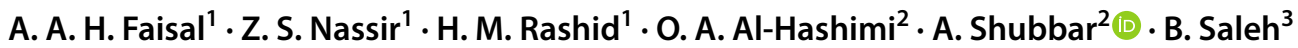

Received: 27 July 2021 / Revised: 10 December 2021 / Accepted: 22 December 2021 / Published online: 8 February 2022

(c) The Author(s) 2022

\begin{abstract}
The current theoretical and experimental study was to thoroughly examine the capability of date stones for scavenging cadmium and lead ions from simulated wastewater. Three layers-artificial neural network (ANN) with 115 batch tests proved that the best conditions achieved the highest sorption efficiency ( $>63 \%$ for $\mathrm{Cd}(\mathrm{II})$ and $>91 \%$ for $\mathrm{Pb}$ (II)) where time $1 \mathrm{~h}, \mathrm{pH}$ 5-6, dosage $5 \mathrm{~g} / 100 \mathrm{~mL}$, speed $100 \mathrm{rpm}$ and temperature $25^{\circ} \mathrm{C}$. A satisfactory matching between the measurements and the ANN outputs was recognized with coefficient of determination greater than $99 \%$. The ANN has also revealed throughout the sensitivity analysis that the initial $\mathrm{pH}$ and contact time with importance of 25 and $39 \%$ for cadmium and lead ions respectively were considered to be the most influential parameters in the removal process. Among Langmuir, Freundlich, and ANN models, the latter one was well fitted the sorption data. This model was substituted in solute transport equation to describe the spatial and temporal distribution of metal ions through the packed column. From the breakthrough curves, the well agreement between the theoretical and measurements (Willmott's index almost greater less than 0.97), the date stones sorbent have had greater tendency to sorb lead ions than that of cadmium ones.
\end{abstract}

Keywords Adsorption $\cdot$ Neural network $\cdot$ Date stones $\cdot$ Modeling $\cdot$ Equilibrium

\section{Introduction}

Water contamination with heavy metals is the increasingly spreading problems in the fields of water conservation and safety. It is linked to a variety of human activities, including mining, metal processing, petroleum, and power generation, as well as metal-based pigments, wastes of electroplating, and other kinds of industrial wastes on a smaller scale (Hashim et al. 2011; Faisal et al. 2018, 2020a, 2021; AlHashimi et al. 2021; Sharma and Naushad 2020). Cadmium and lead ions have long been a source of concern in the

Editorial responsibility: Maryam Shabani.

A. Shubbar

A.A.Shubbar@1jmu.ac.uk

1 Department of Environmental Engineering, College of Engineering, University of Baghdad, Baghdad, Iraq

2 School of Civil Engineering and Built Environment, Liverpool John Moores University, Liverpool, UK

3 Mechanical Engineering Department, College of Engineering, Taif University, P.O. Box 11099, Taif 21944, Saudi Arabia ecosystem due to their toxicity to living things. Cadmium can cause, kidney malfunction, bronchitis, respiratory diseases, and reproduction issues, while lead ions are the reason for the damage of the hepatic, renal, and central nervous system damages, as well as hypertension, decreased cognitive capacity, etc., (Koldabadi et al. 2012).

There are many methods for treating effluents contaminated by metals, but the best method depends on the pollutant concentration and the cost of treatment (Hilal et al. 2012). Chemical precipitation, electroplating, and ion exchange are some of the techniques utilized. Because of its minimal cost, simplest design, operational simplicity, and intolerance to poisonous substances, the adsorption method has emerged as one of the most promising techniques. Activated carbons, which are commonly used for wastewater treatment, cost between $\$ 1500$ and 2000 per ton including $10-15 \%$ loss when regeneration is required. The use of cheap sorbents rather than the expensive ones has been extensively studied (Samra et al. 2014). The date stones are the costprohibitive source available from over 35 million of palm trees in Iraq according to the Ministry of Agriculture, Iraq. The date stone is the solid part comprising the seed coming from the fruit of the palm trees planted in hot and tropical 
countries (Samra et al. 2014). Due to the widespread of this solid waste, the exhausted sorbent is not regenerated and the incineration may be the suitable solution for managing of such material; however, the necessity for disposing of produced ash enriched with metal ions in a more secured landfills is recommended (Marques et al. 1999). Many governorates of Iraq have produced huge quantities of date stones reaching 645,000 tons through the summer of 2009 according to the records from Ministry of Planning. The preparation of each ton from date stones after taking the costs of transportation, cleaning, grinding and electrical energy into account requires approximately US\$ 300 .

Previous studies such as Hansen et al. (2010), Babakhouya et al. (2010), Chatterjee and Schiewer (2011), Saka et al. (2012), Pugazhendhi et al. (2018), Petrella et al. (2018), Mujtaba Munir et al. (2020) have obviously proved the significance of using the most inexpensive and abundant sorbent for the decontamination of metals in the remediation process. In this direction, the removal of lead ions by Antep pistachio (Pistacia Vera L.) shells and applying 3 layers ANN model to estimate the performance of process was implemented (Yetilmezsoy and Demirel 2008). The sorption of cadmium and lead ions onto activated carbons prepared from date stones using different activation methods was tested (El-Hendawy 2009). The bio-sorption of chromium ions in the columns packed with Agave lechuguilla was analyzed (Romero-González et al. 2009). The removal of nickel ions using Aegle marmelos fruit shell as adsorbent in combination with application of ANN model was investigated (Pandharipande and Deshmukh 2013). Pips of olive was added to eliminate of $\mathrm{Pb}$ (II) and $\mathrm{Cd}$ (II) from polluted water, and evaluation of removal was achieved by set of experimental tests with the aid of ANN model (Faisal and Nassir 2016; Faisal et al. 2020b). Also, different rice wastes, hyacinth roots, neem leaves and coconut shells were applied to remove of $\mathrm{Pb}(\mathrm{II})$ from aqueous solution and the behavior of removal has been simulated by ANN (Singha et al. 2015). Leaves of rubber, mango and jackfruit are applied for cadmium remediation from simulated wastewater in the packed bed columns. Results proved that the genetic algorithm (GA) in combination with ANN has a high ability in the prediction of cadmium removal efficiency versus influent variables (Nag et al. 2019). The GA-ANN hybrid system was successfully predicted the removal efficiency of $\mathrm{Cr}(\mathrm{VI})$ using mango, jackfruit, and rubber leaves (Nag et al. 2020). Multiple linear regression (MLR) and GA modeling were used to eliminate of $\mathrm{Cu}$ (II) by Chitosan-nanoSiO ${ }_{2}$ nanocomposite from aqueous solution (Bhattacharya et al. 2021).

Formulation of sorption measurements with suitable relationship to determine the contaminant distribution between solid and liquid phases considers a unique topic because this relation can use effectively in the designing of sorption units. Equilibrium isotherm relationship correlated between the contaminant concentrations in the mentioned phases can be formulated by the sorption models like Langmuir, Freundlich, Elovich, Temkin, and others (Hamdaoui and Naffrechoux 2007). Therefore, this work aims to (i) investigate the effective application of date stones as an inexpensive bio-sorbent for eliminating of cadmium and lead ions from the simulated wastewater, (ii) specify the most influential parameter affected on this process based on sensitivity analysis, (iii) use ANN technique for the description of the equilibrium/non-equilibrium bio-sorption process under consideration at different temperatures, (iv) investigate the possibility of incorporating the transport equation with ANN outputs to describe the migration of metal ions measured physically along the column packed with date stones.

\section{Modeling of sorption measurements and contaminant transport}

\section{Isotherm models}

Isotherms have correlated between the residual concentration of sorbate in the bulk and the magnitude of sorbent that has been sorbed at the surface of the sorbent (Zheng et al. 2009). Langmuir, Freundlich, and others are examples of sorption isotherm models that have been used extensively in previous studies. The model of Langmuir presumes that a sorbate monolayer forms on the sorbent's surface. The Langmuir formula can be written as follows:

$q_{e}=\frac{q_{m} b C_{e}}{1+b C_{e}}$

where $q_{e}$ is the sorbate concentration partitioned on the sorbent grains $(\mathrm{mg} / \mathrm{g}), C_{e}$ is the sorbate concentration at equilibrium $(\mathrm{mg} / \mathrm{L}), q_{m}$ is the maximum mass of contaminant sorbed per unit mass of sorbent $(\mathrm{mg} / \mathrm{g})$, and $b$ is the saturation coefficient $(\mathrm{L} / \mathrm{mg})$.

The Freundlich model is distinguished by sorption that continues as the chemical concentration in the water rises, as well as its nonlinear nature. This is can be illustrated in Eq. 2 as follows:

$q_{e}=K_{F} C_{e}^{1 / n}$

where $K_{F}$ is the Freundlich equilibrium constant (mg/mg) and $n$ is the sorption affinity.

\section{The ANN model}

Previous studies introduced the ANNs as an important alternative approach for finding the complex relationship between different operational conditions. This network has a high ability for establishing a relationship between input-output 
data because it represents an information processing tool. This requires to extract the predominant features from a database that entered such network. ANN includes powerful predictive models to understand, solve and thereby achieve ability for predicting accurately (Yetilmezsoy and Demirel 2008). The working theory of natural networks of biological neurons influenced ANN. A node or neuron is the principal processing element of a neural network. The weighted number of the input signals from the preceding neuron is used to measure the neuron impulse or output of a node. A neuron's learning capacity is achieved by changing the weights in accordance with the selected learning algorithm. The architecture of ANN is composed of input, hidden, and output layers, and the mechanism is iterative. The number of neurons in the output and input layers is proportional to the number of output and input parameters, while in the hidden layer, this number is a crucial decision; however, there is no set formula for determining this number (Kabuba and Bafubiandi 2013).

\section{Contaminant transport equation}

Three processes regulate the movement of pollutants in a porous medium: advective-dispersive and sorption of the solute through the reactive matrix. The relationship describing the interaction between the reactive matrix and the solute can be solved simultaneously with transport equation to simulate non-conservative contaminant transport through reactive media. The following is the one-dimensional advection-dispersion equation:

$n \frac{\partial C}{\partial t}=n D_{z} \frac{\partial^{2} C}{\partial Z^{2}}-n V_{z} \frac{\partial C}{\partial Z}-\rho_{b} \frac{\partial q}{\partial t}$

where $V_{z}$ is the interstitial velocity and $n$ is the reactive medium's effective porosity, $q$ is the quantity of contaminant sorbed on the reactive matrix. Once taking the sorption isotherms into account and presumably $q$ is a function of $C$, the transport equation Eq. 3 can be written as:

$\frac{\partial C}{\partial t}=\left(\frac{D_{z}}{R}\right) \frac{\partial^{2} C}{\partial Z^{2}}-\left(\frac{V_{z}}{R}\right) \frac{\partial C}{\partial Z}$

where $R$ is the factor of retardation at which:

$R=1+\frac{\rho_{b}}{n} \frac{\partial q}{\partial C}$

Equation 4 relates contaminant concentration in the column test to the distance $z$ and subsequent time $t$. The breakthrough curve resulted from the solution of Eq. 4 and the concomitant plotted curves can be valuable for an optimum design in the sorption process. The $\mathrm{S}$-shaped breakthrough curves for the contaminant effluent from the column depict the breakthrough point at which the mass transfer zone has just reached the tip of the column (Shaverdi 2012). The analytical solution of Eq. 4 is tedious and cumbersome and therefore was formulated and solved by the finite difference numerical method as shown in Eq. 6:

$$
\begin{aligned}
C_{i}^{n+1}= & C_{i}^{n}+\left(\frac{\Delta t}{R}\right)\left(D_{z}\right) C_{i}^{n+1}\left(\frac{C_{i-1}^{n}-2 C_{i}^{n}+C_{i+1}^{n}}{(\Delta z)^{2}}\right) \\
& -\left(\frac{\Delta t}{R}\right)\left(V_{z}\right)\left(\frac{C_{i}^{n}-C_{i-1}^{n}}{\Delta z}\right)
\end{aligned}
$$

where the scripts $n+1$ and $n$ stand for the next and current time interval, respectively; $\Delta t=t^{n+1}-t^{n}$ is the size of the time interval as well as the grid notations as $i, i+1$, and $i-1$.

The portion of contaminant retained in the sorbent (described by R in Eq. 6) has been elucidated by the ANN approach. The construction of a computer program to apply the discretized algebraic equations in conjunction with ANN was implemented by MATLAB 7.9.

\section{Materials and methods}

\section{Materials}

A certain amount of date stones was dried at $100{ }^{\circ} \mathrm{C}$ in an oven for almost one day. To achieve a size range of 125 to $710 \mu \mathrm{m}$, the stock was pounded and sieved as shown in Fig. 1a. The main characteristics of this material are included: surface area, actual density, apparent density, porosity, cation exchange capacity and initial $\mathrm{pH}$ of 0.416 $\mathrm{m}^{2} / \mathrm{g}, 1.418 \mathrm{~g} / \mathrm{cm}^{3}, 0.567 \mathrm{~g} / \mathrm{cm}^{3}, 0.45,210 \mathrm{meq} / 100 \mathrm{~g}$ and 3.27, respectively. The composition of data stones is included hemicelluloses, cellulose, lignin and ash with percentages of $54,21,23$, and $1.1 \%$, respectively.

Stock solutions of $1000 \mathrm{mg} / \mathrm{L}$ cadmium and lead nitrates $\mathrm{Cd}\left(\mathrm{NO}_{3}\right)_{2}, \mathrm{~Pb}\left(\mathrm{NO}_{3}\right)_{2}$ (manufactured by BDH, England) were prepared and adjusted at certain $\mathrm{pH}$ value by $0.1 \mathrm{M}$ sodium hydroxide (WTW, Bench model, Germany). The stock solutions that had been intended for the preparation of different concentrations of cadmium and lead ions were kept at $25^{\circ} \mathrm{C}$.

\section{Batch experiments}

The main goal of the batch experiments was to determine to what extent the date stones are capable of removing the cadmium and lead ions. To study the sorption trend and obtain the equilibrium sorption isotherm curves, weighed amounts of pounded date stones were brought into contact with $100 \mathrm{~mL}$ heavy metal-bearing solution in $250-\mathrm{mL}$ flasks and then vigorously agitated at fixed agitation speed and time. An aliquot of $20 \mathrm{~mL}$ was withdrawn to be filtered out via Wattmann filtration paper No.1. The residual out of $10 \mathrm{~mL}$ filtrate and the initial contaminant concentrations 

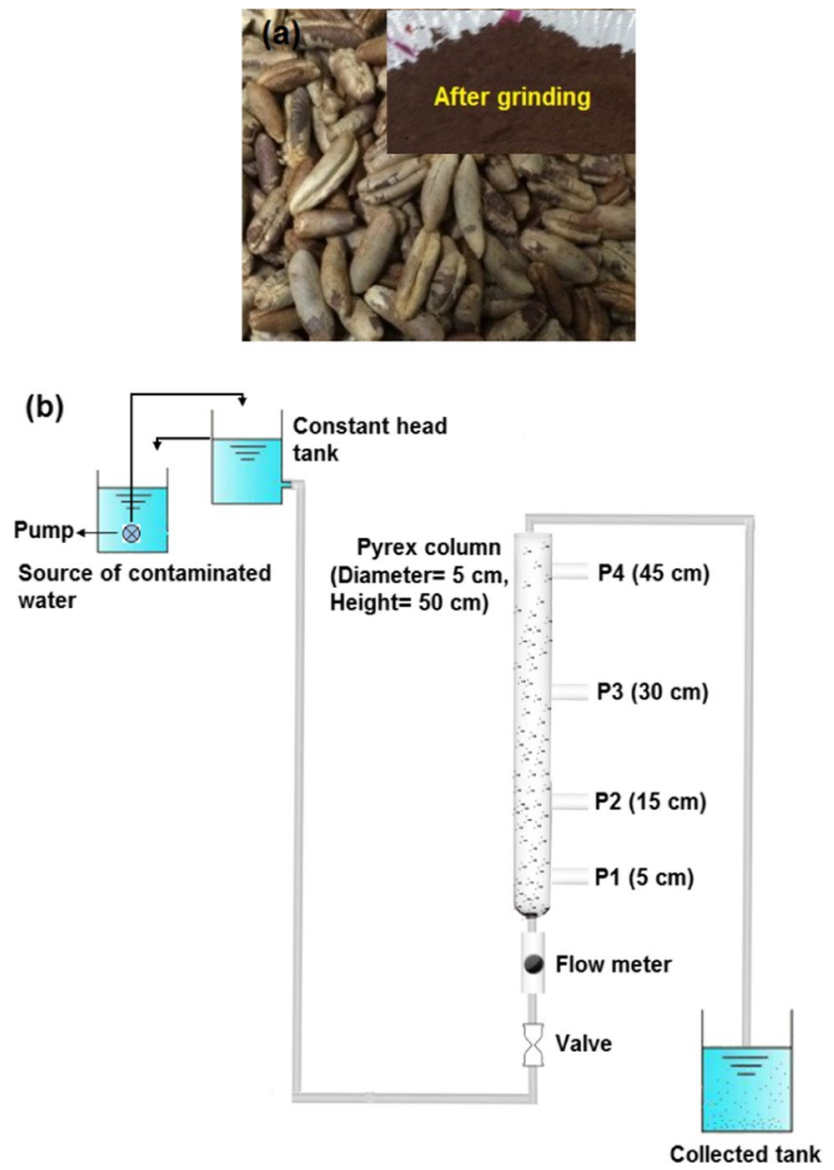

Fig. 1 a Physical appearance of date stones before and after grinding, b schematic diagram of column setup used for monitoring the migration of cadmium and lead ions along date stones sorbent

have been measured via the atomic absorption spectrophotometer (AAS) (Shimadzu, Japan). The quantity of the sorbate retained per unit mass of sorbent was calculated making use of Eq. 7:

$q_{e}=\frac{V\left(C_{i}-C_{f}\right)}{m}$

The sorption isotherm for $q_{e}$ asaf unctionof $c_{f}$ has consequently been plotted, and the corresponding removal efficacy, Eq. 8, was calculated thereafter:

$R=\frac{\left(C_{i}-C_{f}\right)}{C_{i}} \times 100$

Several batch experimental runs were conducted for different bio-sorbent masses from 0.01 to $8 \mathrm{~g} / 100 \mathrm{~mL}$, while the values of $\mathrm{pH}, C_{i}$, contact time, and agitation speed ranged from 2 to 6,10 to $240 \mathrm{~min}, 50$ to $250 \mathrm{mg} / \mathrm{L}$, and 50-250 rpm. A range of temperatures of 20 to $60{ }^{\circ} \mathrm{C}$ were intended to examine the impact of temperature on the biosorption process using a shaker (Edmund Buhler SM25,
Germany). Each point for sorption measurements is the average for three readings. The percentage of error for these readings was very low $(<1 \%)$; so, error bars have excluded in the figures related to sorption tests.

\section{Column experiments}

Column simulations are a one-dimensional approximation of a real-flow process used to assess the efficiency of reactive media that have been chosen as bio-sorbents based on the extent of contaminant elimination. To simulate and then measure the remedial mechanism inside the reactive substance under consideration, an upward flow column test was conducted and worked with an artificial metal polluted solution. A 50-cm-high, 5-cm-diameter Pyrex column as plotted schematically in Fig. 1b was designed to investigate the contaminant's spatial and temporal migration. Influent fluid was fed upwards from a tank with a steady head which remained constant for each flow rate depended on the usage of constant head tank, pump (CHEM-TECH CTPD4HS1-PAP1-G19 PUMP), valve, and flow meter (Cole-Parmer, model type LZM-6T, China, 0.5 to 4.0 LPM) as clear in Fig. 1b. The flow rate was measured by flow meter and also check by determination the amount of polluted water accumulated in collected tank (Fig. 1b) over a period of time. The column was supplied with ports for sampling at locations measured from the base of bed: P1 $(5 \mathrm{~cm}), \mathrm{P} 2(15 \mathrm{~cm}), \mathrm{P} 3(30 \mathrm{~cm})$, and P4 $(45 \mathrm{~cm})$.

Owing to the sorption isotherms, all column tests have been conducted at room temperature. The column must be filled with date stones sorbent, and the distilled water was allowed to flow through the packed bed in the upward direction. This type of flow will push the air in front of it to prevent the air entrapment. The constant head feeding tank containing the contaminants (cadmium and lead ions) was to supply the packed column. The contaminant concentrations in water samples collected from the described ports were tracked on a regular basis (almost two days at different periods of time).

\section{Results and discussion}

\section{ANN model creation}

The performance of cadmium and lead ions removal from water by bio-sorption process was correlated using training algorithm of Levenberg-Marquardt backpropagation (LMA) within ANN model. The MATLAB package version 7.10.0.499 (R2010a) was used to determine this algorithm. The number of layers and nodes with the nature of the transfer functions define the topology of the neural model. The most critical stage in the construction of such model is to optimize the ANN topology, which can be accomplished by splitting the measurements into training, validation and testing subsets. 
The first subset can use to assess the network's quality, and the second one is utilized to assess the trained network's performance and generalization capacity. ANN developed in this work depended on the usage of linear transfer function (purelin) and tangent sigmoid transfer function (tansig) at output and hidden layers, respectively. Several conditions like initial concentration, sorbent dose, agitation time, initial $\mathrm{pH}$, number of rpm's, and temperature have all been the input variables to the feed ANN. Furthermore, the performance variable as response was chosen to be the removal efficiency as percentage. In order to optimize the network and as an initial guess, a couple of neurons have been used in the embedded layer such that the number of neurons was eventually expanded before the mean square error (MSE) values were reached (Table 1). Figure 2 reveals how the MSE can be related to the number of neurons for a LMA algorithm.

For developed network, the MSE of cadmium onto date stones sorbent was changed from 0.002 for 2 embedded neurons, as shown in Table 1 and Fig. 2, the MSE decreased significantly to be 0.001 at 4 neurons. An optimum case of eleven hidden neurons was selected as the MSE had been dropped to 0.00031 . The rise of the MSE magnitude was as a result of an abrupt change from eleven to sixteen neurons. The features of the MSE output index and the input vector used in this analysis are responsible for this change (Yetilmezsoy and Demirel 2008). Figure 2 shows that for lead ions, the MSE varies in lockstep with the number of embedded neurons, with the strongest value equal to 9 .

Since the variations between training error and validation one started to increase and because of the partitioning of the lead and cadmium ions on the date stones sorbent; the training has been terminated after thirty-seven epochs for lead and fifty-four epochs for cadmium. The MSE for the LMA are shown in Fig. 3 as preparation, validation, and evaluation which are chosen according to the highest correlation coefficient values as shown in Fig. 4.

\section{Dosage of bio-sorbents and their effects}

The effect of date stones sorbent dosages on the removal efficiencies of metal ions adopted in the present tests is investigated at $C_{i}=50 \mathrm{mg} / \mathrm{L}$, agitation speed $=250 \mathrm{rpm}$, and time $=1 \mathrm{~h}$ for temperature of $25^{\circ} \mathrm{C}$ as obvious in Fig. $5 \mathrm{a}$. Results in this figure signified that the percentage removal of $\mathrm{Cd}(\mathrm{II})$ ions varied from 10 to $63 \%$ due to sorbent mass variation from 0.01 to $5 \mathrm{~g}$ for certain $C_{i}$. The larger the number of the grams of the sorbent mass, the greater removal is attained (Amarasinghe and Williams 2007). It is evidence that a very marginal change in the sorption efficiencies of $\mathrm{Cd}(\mathrm{II})$ ions occurred with changing the bio-sorbent dosage from 5 to $8 \mathrm{~g} / 100 \mathrm{~mL}$; therefore, $5 \mathrm{~g} / 100 \mathrm{~mL}$ was selected to conduct other batch experiments. Furthermore, despite a disparity in the value of the better sorbent dose $(=5 \mathrm{~g} /$
Table 1 Variation of MSE with neurons number in the training set for (a) cadmium and (b) lead ions

\begin{tabular}{lll}
\hline No. of neurons & $\mathrm{Cd}(\mathrm{II})$ & $\mathrm{Pb}(\mathrm{II})$ \\
\hline 2 & $2.000 \times 10^{-3}$ & $4.400 \times 10^{-3}$ \\
3 & $1.400 \times 10^{-3}$ & $2.000 \times 10^{-3}$ \\
4 & $1.000 \times 10^{-3}$ & $0.670 \times 10^{-3}$ \\
5 & $0.900 \times 10^{-3}$ & $1.800 \times 10^{-3}$ \\
6 & $0.990 \times 10^{-3}$ & $1.200 \times 10^{-3}$ \\
7 & $0.500 \times 10^{-3}$ & $0.890 \times 10^{-3}$ \\
8 & $0.800 \times 10^{-3}$ & $0.760 \times 10^{-3}$ \\
9 & $0.600 \times 10^{-3}$ & $0.560 \times 10^{-3}$ \\
10 & $0.400 \times 10^{-3}$ & $0.930 \times 10^{-3}$ \\
11 & $0.311 \times 10^{-3}$ & $1.300 \times 10^{-3}$ \\
12 & $0.740 \times 10^{-3}$ & $0.950 \times 10^{-3}$ \\
13 & $0.580 \times 10^{-3}$ & $0.950 \times 10^{-3}-3$ \\
14 & $0.920 \times 10^{-3}$ & $0.870 \times 10^{-3}$ \\
15 & $0.880 \times 10^{-3}$ & $0.610 \times 10^{-3}$ \\
16 & $0.660 \times 10^{-3}$ & $1.200 \times 10^{-3}$ \\
\hline
\end{tabular}

$100 \mathrm{~mL}$ ) with the corresponding efficiency of the listed sorbent, Fig. $5 \mathrm{~b}$ reveals that the lead removal efficiencies into the mentioned sorbent follow the same pattern as previously stated. As a function of bio-sorbent dose, Fig. 5a, b shows a comparison of experimental outcomes and ANN model outputs. Correlation coefficients greater than 0.99 indicate that these two sets of data are in fair agreement.

\section{Contact time and the solution's initial pH}

Figure 5 explains the influence of initial $\mathrm{pH}$ and contact period on $\mathrm{Cd}(\mathrm{II})$ and $\mathrm{Pb}$ (II) ion sorption using $5 \mathrm{~g}$ of date stones sorbent per $100 \mathrm{~mL}$ of polluted solution at $25^{\circ} \mathrm{C}$. The sorption uptake was noticed as high at the early stages of contact time then subsided till reaching equilibrium. This elucidates the availability of the fresh reactive sorption sites earlier. Once theses vacant sites become sorbed with contaminants, no more sorption sites would be ready to receive further contaminants causing a decline in the removal rate (El-Sayed et al. 2010).

The results of the experiments show that the initial $\mathrm{pH}$ has a substantial impact on bio-sorption efficiency. At $\mathrm{pH}$ 2.0, metal ions were removed owing to the high concentrations of hydrogen ions that have interfered with the ions of metals for binding sites. At $\mathrm{pH}$ adjacent to 6 , the elimination of metal ions is increased to higher levels, which may be attributed to a reduction in rivalry between hydrogen and metal species for vacant sites (Alkan et al. 2008). The optimum cadmium and lead ion removal efficiencies were clearly reached at an initial $\mathrm{pH}$ of 6 and 5 , respectively. The findings showed that equilibrium was reached after one hour of agitation and that bio-sorption remained roughly constant as agitation time increased. Over a variety of experiments, a contact time of 10 
Fig. 2 Variation of MSE with neurons number at hidden layer for $\mathbf{a}$ cadmium and $\mathbf{b}$ lead ions using algorithm of LevenbergMarquardt
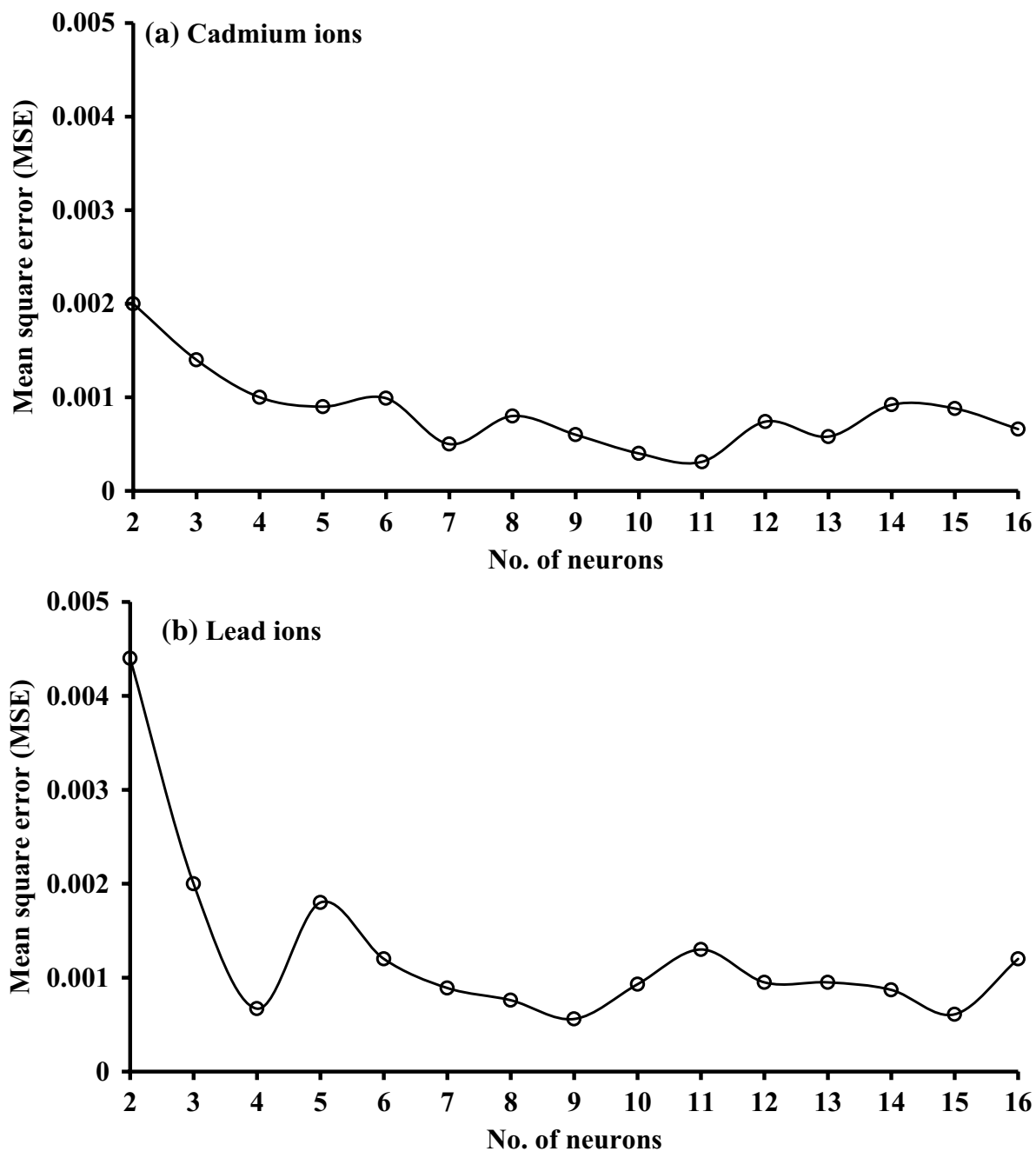

or 30 min was adequate to achieve equilibrium, implying that the bio-sorption process was conveniently rapid. The time of agitation beyond one hour seems not feasible since similar experimental results are obtained. The ANN model gives a clear explanation for the experimental findings, as shown in Fig. 5, with coefficient of correlation greater than 0.92 .

\section{Initial concentration}

The best bio-sorbent dose $5 \mathrm{~g}$ was added into $100 \mathrm{~mL}$ of aqueous phase at the best predetermined $\mathrm{pH}$ value to identify the efficiency of $\mathrm{Cd}(\mathrm{II})$ and $\mathrm{Pb}$ (II) ions removal as varying their initial concentrations from 50 to $250 \mathrm{mg} / \mathrm{L}$. Table 2 explains that the removal efficiencies of metal ions under consideration onto the date stones sorbent were decreased significantly with an increase in the initial metal concentrations. This may result from the significant binding sites present in the bio-sorbent dose chosen. With a coefficient of correlation greater than 0.98 , the ANN outputs are consistent with the experimental results for various initial concentrations of adopted pollutants, as exhibited in Table 2 .

\section{Agitation speed}

Figure 6 explains the change in the removal percentages of $\mathrm{Cd}$ (II) and $\mathrm{Pb}$ (II) versus the values of agitation speed at the best conditions specified from the previous tests where certain percentage of metal ions $(<30 \%)$ was removed at zero agitation speed. It is obvious that the sorption rate is directly proportional to the agitation speed and this is due to enhanced mass transfer from the liquid phase to the particles surfaces (Anwar et al. 2010). The measurements show that $100 \mathrm{rpm}$ agitation is necessary to guarantee that all sorption sites are nearly accessible for metal uptake. With a correlation coefficient $>0.99$, the ANN model provides a strong prediction for the experimental results, as shown in Fig. 6.

\section{Temperature}

The sorption of $\mathrm{Cd}(\mathrm{II})$ and $\mathrm{Pb}(\mathrm{II})$ ions onto date stones sorbent was reasonably temperature dependent at an almost one-hour time of equilibrium according to the experimental results (Table 3 ). As the temperature was raised from 20 to 


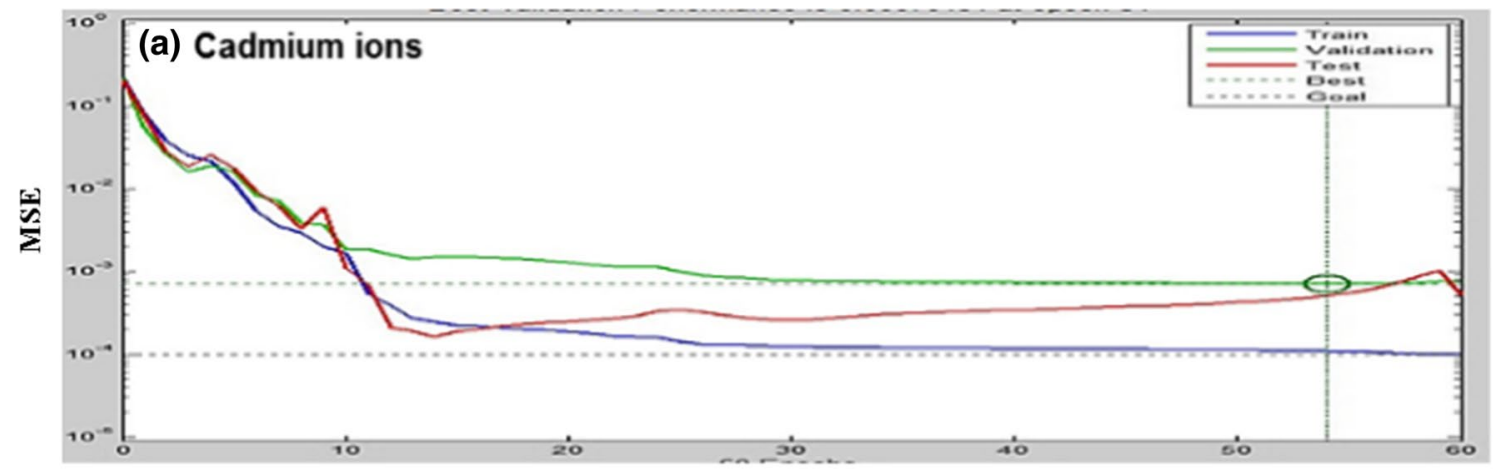

Epochs

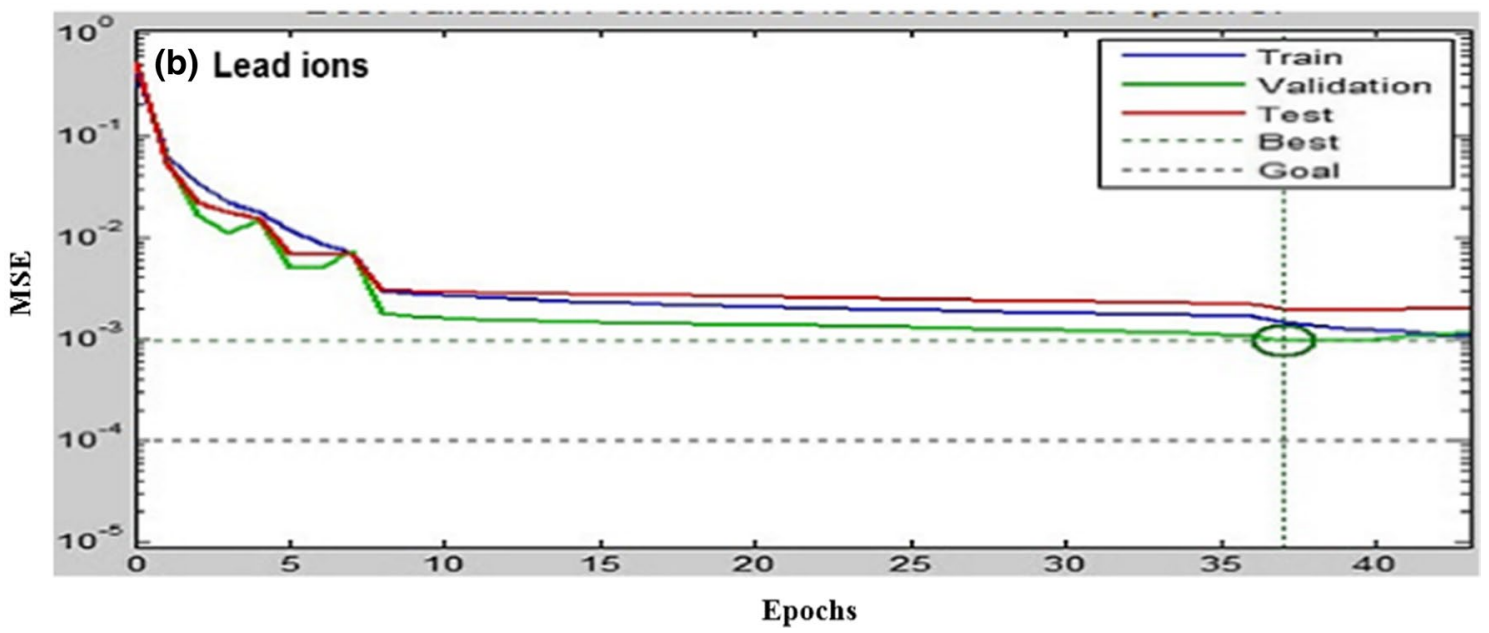

Fig. 3 Mean square errors of training, validation, and testing for a cadmium and $\mathbf{b}$ lead ions using algorithm of Levenberg-Marquardt

60 degrees Celsius, cadmium ion sorption rose by 63 to 67 percent, while lead ion reduction percentages remained constant (85-99 percent). This action is perhaps resulted from an improvement in the metal diffusion rate through the external boundary layer and the sorbent particles' internal pores (Alkan et al. 2008). Table 3 shows that the ANN model's projections and the experimental results are in strong agreement with coefficient of correlation of 0.949 .

\section{Adsorption characteristics}

The maximal sorption capacities of date stones sorbent are calculated using equilibrium bio-sorption studies. The isotherms for adopted metals ions have been determined at best values of operational conditions specified previously. Figure 7 plots the sorption isotherms for interaction of metals ions and date stones sorbent using Freundlich, Langmuir and ANN models. To measure the full sorption capacities of date stones sorbent, studies of equilibrium bio-sorption were performed. Isotherms have a fast sorption rate in the early stages and reach asymptotic levels as concentrations increase. In addition to $\mathrm{Cd}(\mathrm{II})$, the date stones sorbent has a greater affinitive property towards $\mathrm{Pb}$ (II), as shown in Fig. 7. As to the Langmuir equation, the maximum sorption capacity for lead is greater than cadmium as shown in Table 4. The difference in hydration energy between $\mathrm{Pb}(\mathrm{II})$ and $\mathrm{Cd}(\mathrm{II})$ may explain why $\mathrm{Pb}(\mathrm{II})$ is adsorbed better than $\mathrm{Cd}(\mathrm{II})$ in this bio-sorbent (Bohli et al. 2013).

For a number of ex-studies, Table 5 lists the maximum sorption capacity for various inexpensive sorbents. It can be observed from this table that the date stones sorbent has sorption capacity comparable with capacities of other identical bio-sorbents; so, this unique property for such byproduct with its costless can represent the major finding for this study. The usability of an adsorbent for practical applications mainly depends on its recyclability (or regeneration) capacity. However, the regeneration process was not studied in this work because of the costless of date stones sorbent; thus, the disposal of exhausted sorbent in the sanitary landfill considers the optimal solution for dealing with such sorbent. When compared to Freundlich and Langmuir models for describing $\mathrm{Cd}$ (II) and $\mathrm{Pb}$ (II) bio-sorption onto date stones, Fig. 7 shows that the ANN model matches the experimental results very well. To define the transport of these metal 

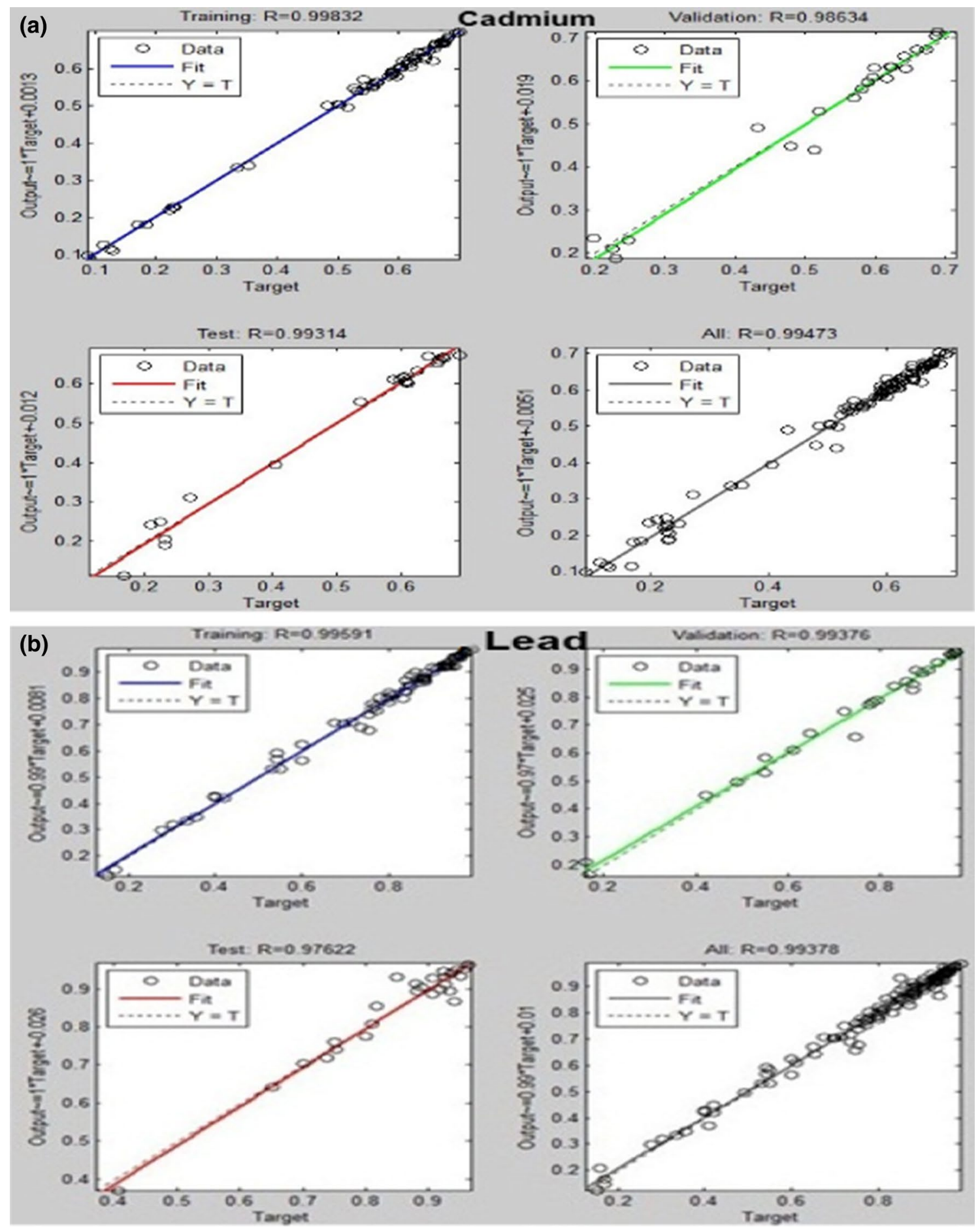

Fig. 4 Regressions of training, validation, and testing for $\mathbf{a}$ cadmium and $\mathbf{b}$ lead ions using algorithm of Levenberg-Marquardt

ions in the packed column, the fifth degree polynomial ANN model outputs (Eqs. 9 and 10) are combined with the advection-dispersion equation.

$$
\begin{aligned}
q_{e}= & 0.14 \times 10^{-1}+3.56 \times 10^{-2} C_{e}-0.11 \\
& \times 10^{-3} C_{e}^{2}-4.97 \\
& \times 10^{-7} C_{e}^{3}+9.4 \times 10^{-9} C_{e}^{4}-3.93 \\
& \times 10^{-11} C_{e}^{5} \text { forcadmium }
\end{aligned}
$$



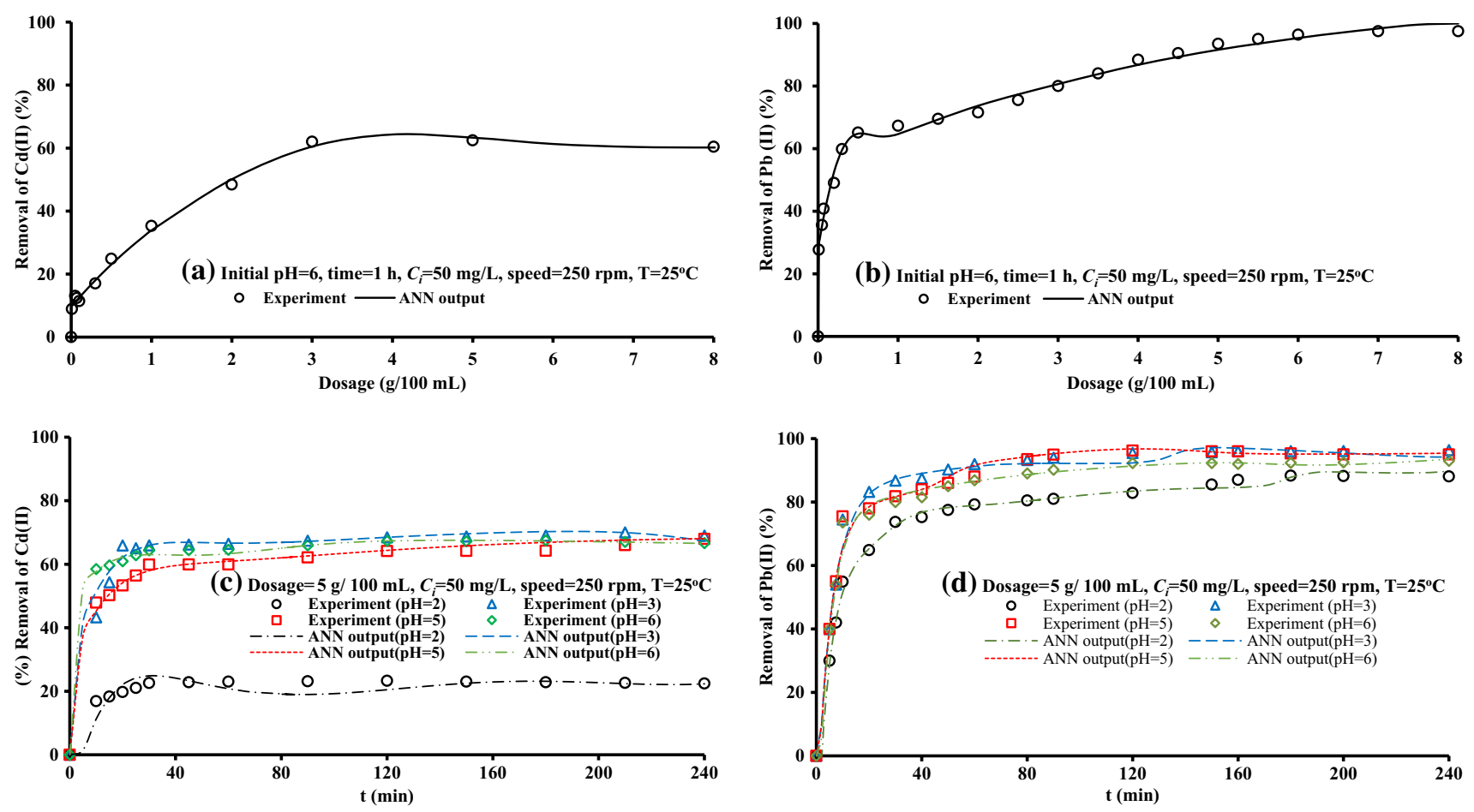

Fig. 5 A comparison between the experimental results and ANN outputs for sorption of cadmium and lead ions onto date stones sorbent as a function of $\mathbf{a}, \mathbf{b}$ sorbent dosage and $\mathbf{c}, \mathbf{d}$ initial $\mathrm{pH}$ and contact time

Table 2 ANN outputs with measurements for removals of cadmium and lead for different initial concentrations at $25^{\circ} \mathrm{C}(\mathrm{t}=1 \mathrm{~h}$, initial $\mathrm{pH}=5-6$, and speed $=250 \mathrm{rpm})$

\begin{tabular}{llllll}
\hline$C_{i}(\mathrm{mg} / \mathrm{L})$ & \multicolumn{2}{l}{ Cadmium $(\%)$} & & \multicolumn{2}{l}{ Lead $(\%)$} \\
\cline { 2 - 3 } \cline { 6 - 6 } & Exp & ANN & & Exp & ANN \\
\hline 50 & 62.23 & 63.31 & & 94.39 & 91.6 \\
100 & 61.67 & 60.71 & & 92 & 90.26 \\
150 & 59.2 & 59.3 & & 91 & 90.73 \\
200 & 56.48 & 56.32 & & 90 & 90.18 \\
250 & 54 & 54 & & 88 & 88.02 \\
\hline
\end{tabular}

$$
\begin{aligned}
q_{e}= & 0.13 \times 10^{-1}+24 \times 10^{-2} C_{e}-17.1 \\
& \times 10^{-3} C_{e}^{2}+18.44 \\
& \times 10^{-4} C_{e}^{3}-7.85 \times 10^{-5} C_{e}^{4}+1.08 \\
& \times 10^{-6} C_{e}^{5} \text { forlead }
\end{aligned}
$$

\section{Sensitivity analysis}

The sensitivity analysis was performed making use of a matrix of the neural net as well as Garson equation (Eq. 11) to determine the relative value of the input variables. Garson (1991), Aleboyeh et al. (2008):

$$
I_{j}=\frac{\sum_{m=1}^{m=N h}\left(\left(\frac{\left|W_{j m}^{i h}\right|}{\sum_{k=1}^{N i}\left|W_{k m}^{i h}\right|}\right) \times\left|W_{m n}^{h o}\right|\right)}{\sum_{k=1}^{k=N i}\left\{\sum_{m=1}^{m=N h}\left(\frac{\left|W_{k m}^{i h}\right|}{\sum_{k=1}^{N i}\left|W_{k m}^{i h}\right|}\right) \times\left|W_{m n}^{h o}\right|\right\}}
$$

where $I j$ denotes the $j$ th input variable's relative value to the output variable and $N i$ and $N h$ denote the number of input and hidden neurons, respectively. The superscripts o, $h$, and $i$ as well as subscripts $n, m$, and $k$ refer to output, hidden, and input neurons, respectively.

In addition to other batch experimental parameters, a 25 percent as relative significance referred to the dominant initial $\mathrm{pH}$ parameter for the uptake of $\mathrm{Cd}(\mathrm{II})$ ions onto the date stones sorbent, whereas 39\% referred to the most influential contact time which has had remarkable impact on the sorption of $\mathrm{Pb}(\mathrm{II})$ as shown in Fig. 8. Many studies, on the other hand, have shown that the dominant variable as well as the impact of each variable is strictly dependent upon the experimental ranges utilized in the proposed model (Yang et al. 2014).

\section{Transport of metal ions in date stones sorbent packed bed}

In this study, a combination of Eq. 6 with Eq. 9 for cadmium and Eq. 10 for lead can be represented by the integrated 
Fig. 6 ANN outputs and measurements for metals removals due to the variation of agitation speed
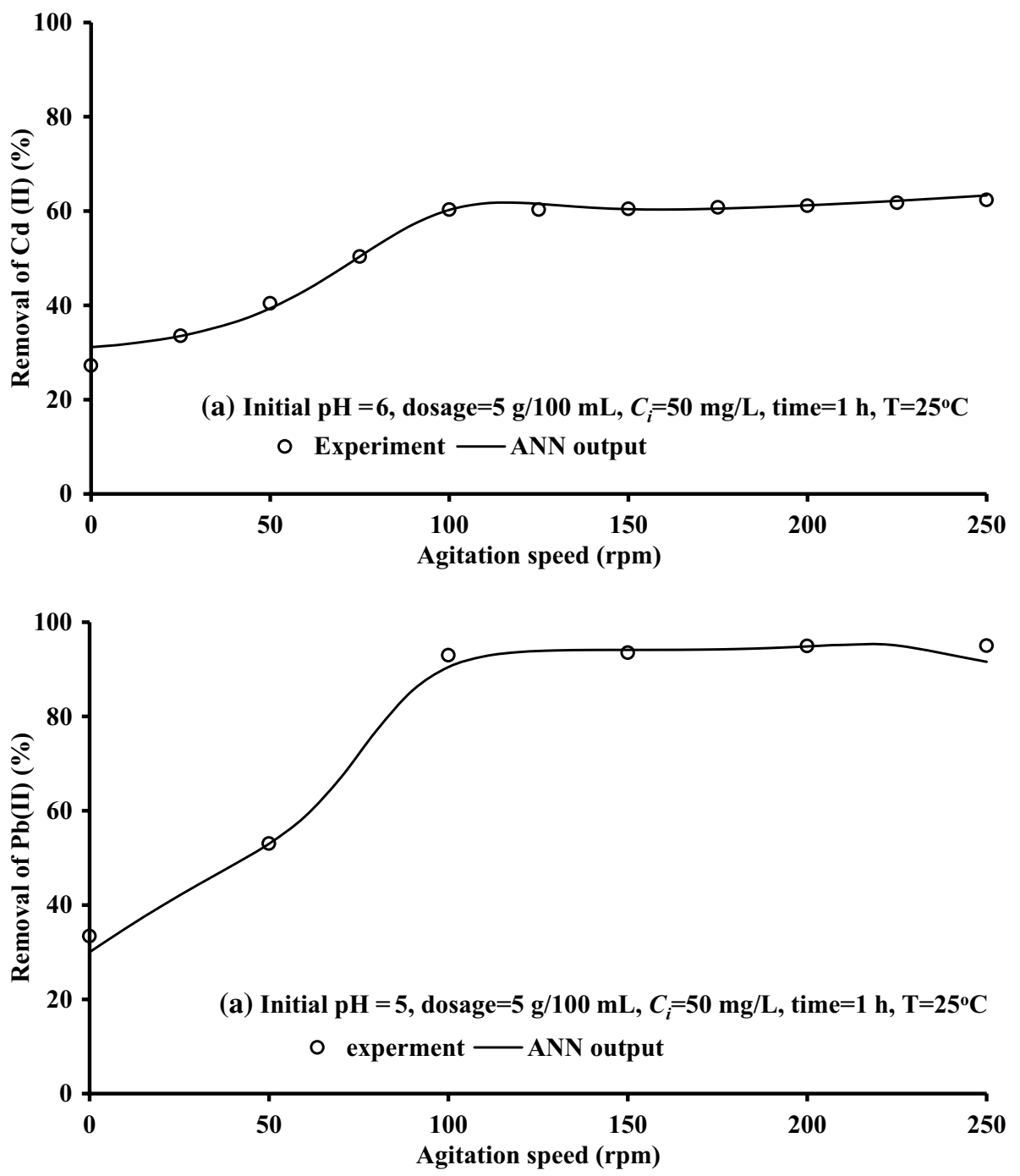

model developed in this analysis to describe the contaminant transport. To solve the model, the metal concentration is set to zero as an initial state, with a boundary condition of $50 \mathrm{mg} / \mathrm{L}$ at the column base and the advective flux for this metal at the column outlet.

The movement of dissolved metals is much restricted throughout the sorbent bed, and this is due to the probable retardation (Fetter 1999). The recovery curves of Cd(II) and $\mathrm{Pb}$ (II) ions at the outlets of ports $\mathrm{P} 1$ to $\mathrm{P} 4$ are plotted in Fig. 9 which reveals a comparison of expected and measured normalized concentrations over time for various flow rates $Q=10$ and $20 \mathrm{~mL} / \mathrm{min}$. The detention time for the contaminant metals in the thicker sorbent bed is rather longer than that in narrower one making an increase in both the sorption efficiency and the bed longevity. According to the USEPA regulations, the permissible levels of $\mathrm{Cd}(\mathrm{II})$ and $\mathrm{Pb}$ (II) in potable water shall not reach 0.005 and $0.015 \mathrm{mg} / \mathrm{L}$, respectively (Hashim et al. 2011).

The longer the detention time, the more contaminants are sorbed within the bed. Unfortunately, the more accumulation of these contaminants reduces the retardation factor since they make the pore channels narrower and consequently higher pore water velocity, and thus no more contaminants are retained within the bed. The figure also suggests that the expected and experimental results are in good agreement as

Table 3 ANN outputs with measurements for removals of cadmium and lead for different temperatures $(\mathrm{t}=1 \mathrm{~h}$, initial $\mathrm{pH}=5-6$, dosage $=5 \mathrm{~g} / 100 \mathrm{~mL}, C_{i}=50 \mathrm{mg} / \mathrm{L}$, speed $=100 \mathrm{rpm}$ )

\begin{tabular}{llllll}
\hline Temp. $\left({ }^{\circ} \mathrm{C}\right)$ & \multicolumn{2}{l}{ Cadmium $(\%)$} & & \multicolumn{2}{l}{ Lead $(\%)$} \\
\cline { 2 - 3 } & Exp & ANN & & Exp & ANN \\
\hline 20 & 63.07 & 59.88 & 85.38 & 85 \\
25 & 63.31 & 62.21 & 91.6 & 93.1 \\
30 & 63.31 & 62.38 & 93.46 & 93.28 \\
40 & 62.64 & 62.62 & 94.69 & 94 \\
50 & 65.17 & 65.74 & 95.88 & 96.4 \\
60 & 69.70 & 69.73 & 99.05 & 98.8 \\
\hline
\end{tabular}


Fig. 7 Comparison between experimental values of sorbed metal ions $\left(q_{e}\right)$ and outputs of ANN, Freundlich, and Langmuir models for ions of cadmium and lead sorbed onto date stones sorbent
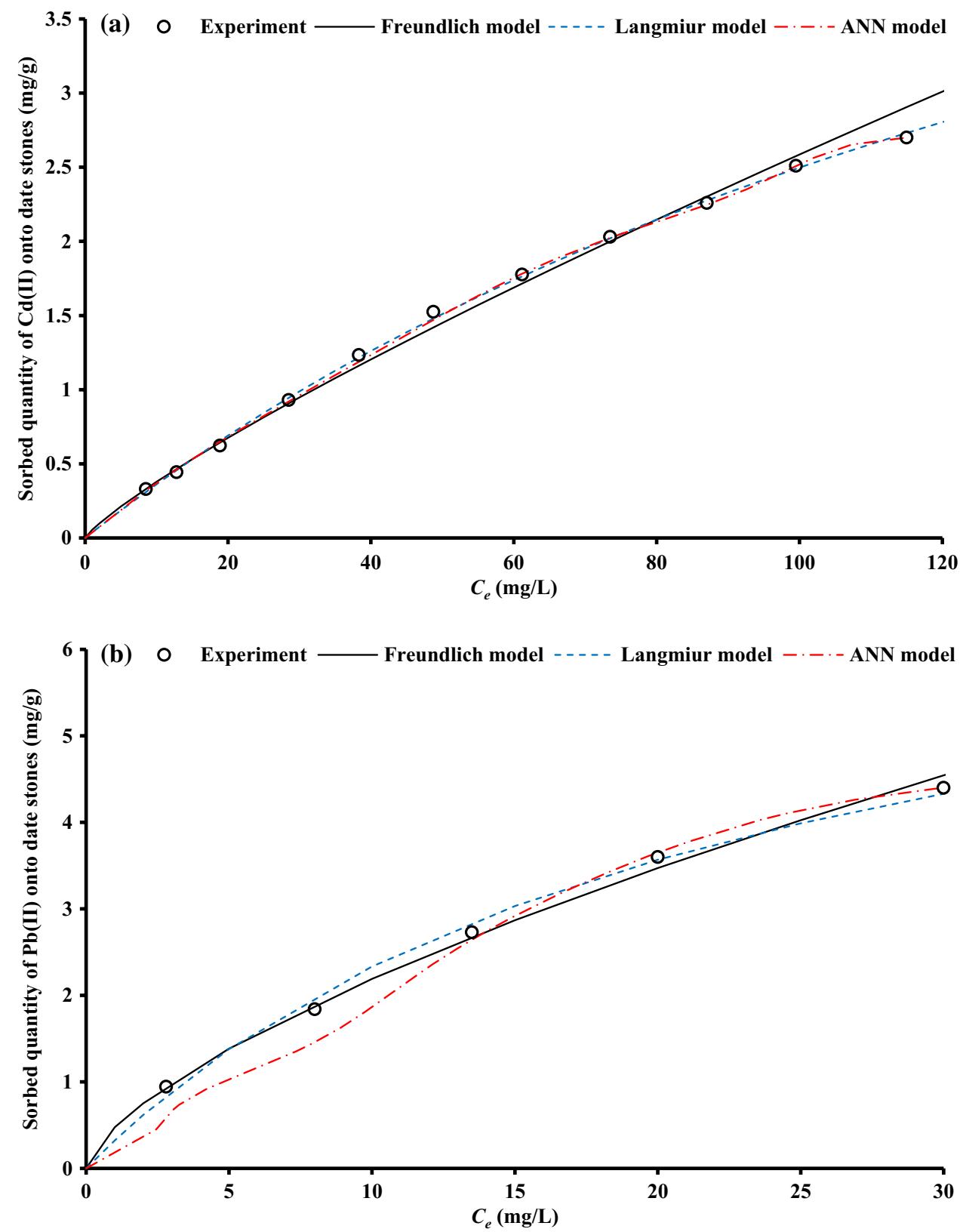

Table 4 Calculated constants of isotherm models with determination coefficients for bio-sorption of cadmium and lead onto date stones

\begin{tabular}{llll}
\hline Model & & Cadmium (\%) & Lead (\%) \\
\hline Freundlich & $K_{F}(\mathrm{mg} / \mathrm{g})(\mathrm{L} / \mathrm{mg})^{1 / \mathrm{n}}$ & 0.0555 & 0.4755 \\
\hline \multirow{4}{*}{ Langmuir } & $n$ & 1.1989 & 1.5069 \\
& $R^{2}$ & 0.9961 & 0.9976 \\
& $b(\mathrm{~L} / \mathrm{mg})$ & 7.233 & 7.573 \\
& $R^{2}$ & 0.00527 & 0.04454 \\
\end{tabular}

estimated from the Willmott's index in Eq. 12. The index ranging from zero (no agreement) up to 1 (perfect agreement) determines to what extent the predicted $\left(P_{i}\right)$ and observed $\left(O_{i}\right)$ results are in agreement (Krause et al. 2005). Since the Willmott's index was almost greater than 0.97 in this study, the numerical solution for the model equation is being highly consistent for the contaminants transport within the bed.

$d=1-\frac{\sum_{i=1}^{n}\left(O_{i}-P_{i}\right)^{2}}{\sum_{i=1}^{n}\left(\left|P_{i}-\bar{O}\right|+\left|O_{i}-\bar{O}\right|\right)^{2}}$ 
Table 5 Maximum sorption capacities for bio-sorption of cadmium and lead ions onto different sorbents

\begin{tabular}{lllll}
\hline Material & \multicolumn{2}{l}{$q_{m}(\mathrm{mg} / \mathrm{g})$} & & References \\
\cline { 2 - 3 } & $\mathrm{Cd}(\mathrm{II})$ & $\mathrm{Pb}(\mathrm{II})$ & \\
\hline Date stones & 7.233 & 7.573 & Present study \\
Shells of Antep pistachios & - & 27.1 & & Yetilmezsoy and Demirel (2008) \\
Walnut shell & - & 3.59 & & Das et al. (2020) \\
Activated carbon of apricot stone & 33.57 & 22.84 & Kobya et al. (2005) \\
Pips of olive & 16.972 & 28.386 & Fiol et al. (2006) \\
& 0.575 & - & Babakhouya et al. (2010) \\
Waste of tea & - & 65 & & Amarasinghe and Williams (2007) \\
Rice husk & - & 11 & & Chuah et al. (2005) \\
Date stones & 0.486 & - & Babakhouya et al. (2010) \\
Activated carbon of saffron leaves & 68.75 & 79.6 & Dowlatshahi et al. (2014) \\
Waste of sago & - & 47 & Quek et al. (1998) \\
Modifed Ziziphus spina-christi stones & 3.90 & 6.83 & Assirey et al. (2020) \\
\hline
\end{tabular}

Figure 9 illustrates the increase in frontal propagation of the contaminants due to the concomitant in the increase in the volumetric flow rate per bed cross-sectional area. This figure indicates that the binding sites of the date stones sorbent have higher affinity towards lead ions in comparison with
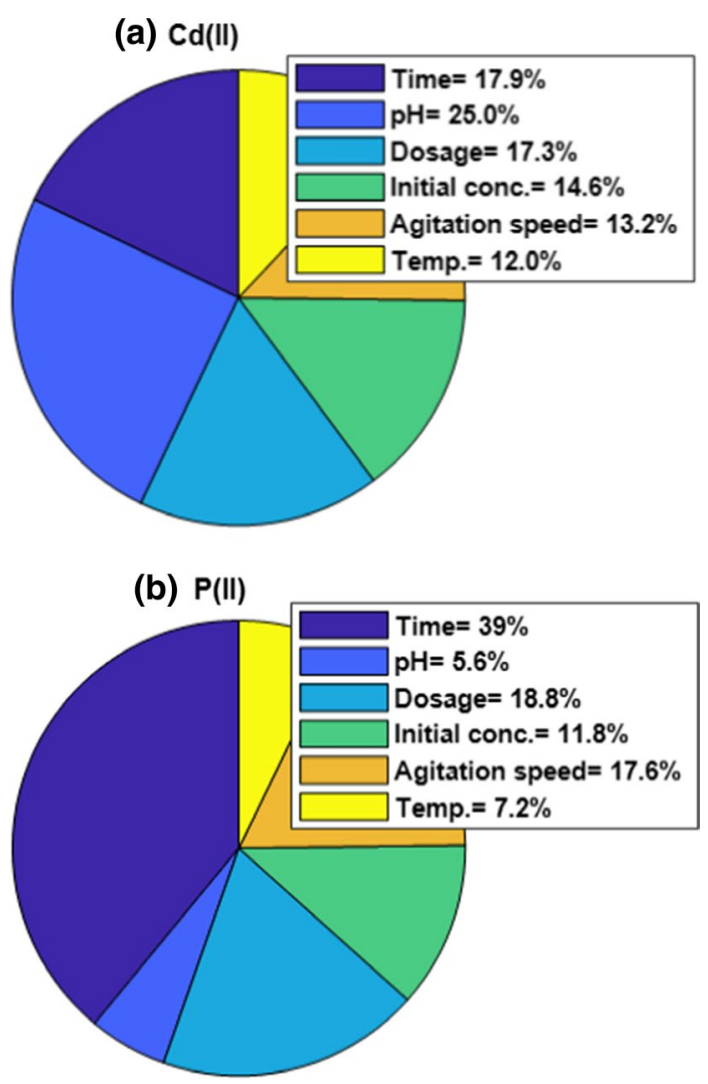

Fig. 8 Sensitivity analysis for uptake of $\mathbf{a}$ cadmium and $\mathbf{b}$ lead ions onto date stones sorbent using artificial neural network that of cadmium ions and these results are consistent with outputs of batch study.

\section{Conclusion}

The best batch experimental conditions corresponding to removal of at least $63 \%$ of the dissolved $\mathrm{Cd}$ (II) and $\mathrm{Pb}$ (II) ions over a predetermined optimum $5 \mathrm{~g} / 100 \mathrm{~mL}$ date stones sorbent dose were outlined as an initial $\mathrm{pH}$ of 5 and 6 for $\mathrm{Pb}$ (II) and $\mathrm{Cd}$ (II) respectively, with speed of utmost $100 \mathrm{rpm}$ agitation and at room temperature $25^{\circ} \mathrm{C}$. According to the Langmuir sorption equation, the highest sorption capacities of $\mathrm{Pb}(\mathrm{II})$ and $\mathrm{Cd}$ (II) onto the date stones sorbent were found to be 7.573 and $7.233 \mathrm{mg} / \mathrm{g}$, respectively. To estimate the efficiency of metal ion removal, ANN of 3 layers with linear transfer function (purelin) and tangent sigmoid transfer function (tansig) at the output and hidden layers, respectively, was proposed to yield better guess for six parametric experimental variables corresponding to at least $99 \%$ correlation. For ANN, the initial $\mathrm{pH}$ of solution and time of contact are corresponding to $25 \%$ for $\mathrm{Cd}(\mathrm{II})$ and $39 \%$ for $\mathrm{Pb}$ (II) significant sorption parameter as most dominant experimental parameters. For recovery curves, the ANN outputs have had well agreement with the measured experimental results such that the Willmott's index had had at least 0.97 . The longevity of the sorbent bed decreases with increasing the contaminant velocity through the bed; the thicker the date stones sorbent bed, the higher the removal of the dissolved metal ions. Both expected and experimental findings showed that the binding sites of date stones sorbent have had higher affinity to $\mathrm{Pb}(\mathrm{II})$ ions than to $\mathrm{Cd}(\mathrm{II})$ ions. 

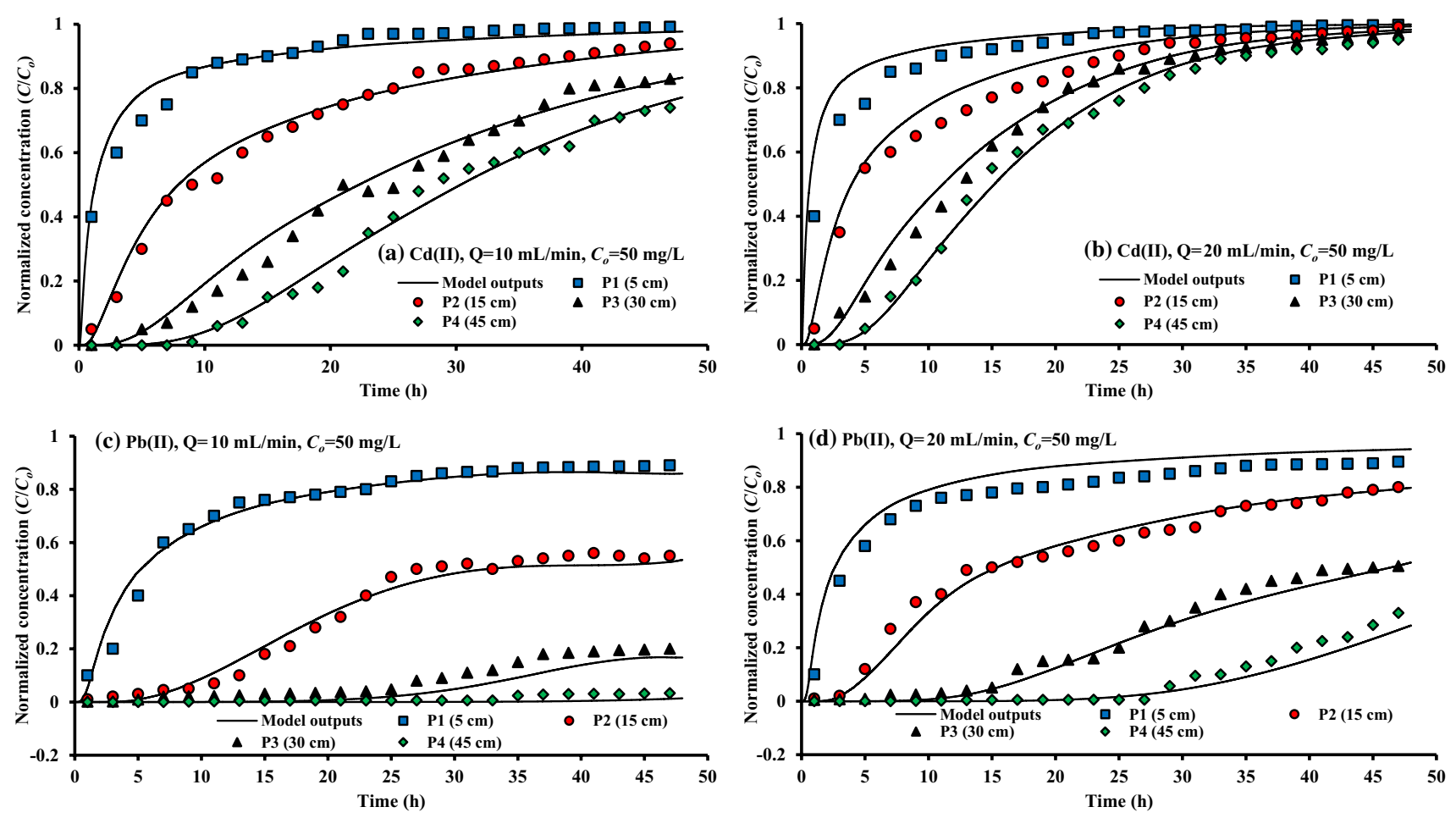

Fig. 9 Measured and predicted propagation curves of metals fronts at certain depths along date stones sorbent bed

Acknowledgements One of the authors (B. Saleh) is grateful to the Taif University Researchers Supporting Project number (TURSP2020/49), Taif University, Taif, Saudi Arabia, for the financial support. Also, the authors would like to gratefully acknowledge the technical support of Environmental Engineering Department/University of Baghdad during this work.

\section{Declarations}

Conflict of interests The authors declare no conflict of interest.

Open Access This article is licensed under a Creative Commons Attribution 4.0 International License, which permits use, sharing, adaptation, distribution and reproduction in any medium or format, as long as you give appropriate credit to the original author(s) and the source, provide a link to the Creative Commons licence, and indicate if changes were made. The images or other third party material in this article are included in the article's Creative Commons licence, unless indicated otherwise in a credit line to the material. If material is not included in the article's Creative Commons licence and your intended use is not permitted by statutory regulation or exceeds the permitted use, you will need to obtain permission directly from the copyright holder. To view a copy of this licence, visit http://creativecommons.org/licenses/by/4.0/.

\section{References}

Aleboyeh A, Kasiri MB, Olya ME, Aleboyeh H (2008) Prediction of azo dye decolorization by $\mathrm{UV} / \mathrm{H}_{2} \mathrm{O}_{2}$ using artificial neural networks. Dye Pigment 77:288-294. https://doi.org/10.1016/j.dyepig. 2007.05.014
Al-Hashimi O, Hashim K, Loffill E et al (2021) A comprehensive review for groundwater contamination and remediation: occurrence, migration and adsorption modelling. Molecules 26:5913. https://doi.org/10.3390/molecules26195913

Alkan M, Kalay B, Doğan M, Demirbaş Ö (2008) Removal of copper ions from aqueous solutions by kaolinite and batch design. J Hazard Mater 153:867-876. https://doi.org/10.1016/j.jhazmat. 2007.09.047

Amarasinghe BMWPK, Williams RA (2007) Tea waste as a low cost adsorbent for the removal of $\mathrm{Cu}$ and $\mathrm{Pb}$ from wastewater. Chem Eng J 132:299-309. https://doi.org/10.1016/j.cej.2007.01.016

Anwar J, Shafique U et al (2010) Removal of Pb(II) and Cd(II) from water by adsorption on peels of banana. Bioresour Technol 101:1752-1755. https://doi.org/10.1016/j.biortech.2009.10.021

Assirey EA, Sirry SM, Burkani HA, Ibrahim MA (2020) Modified Ziziphus spina-christi stones as green route for the removal of heavy metals. Sci Rep 10:20557. https://doi.org/10.1038/ s41598-020-76810-y

Babakhouya N, Aksas H, Boughrara S, Louhab K (2010) Adsorption of $\mathrm{Cd}(\mathrm{II})$ ions from aqueous solution using mixed sorbents prepared from olive stone and date pit. J Appl Sci 10:2316-2321. https:// doi.org/10.3923/jas.2010.2316.2321

Bhattacharya S, Bar N, Rajbansi B, Das SK (2021) Adsorptive elimination of $\mathrm{Cu}$ (II) from aqueous solution by chitosan-nanoSiO $\mathrm{S}_{2}$ nanocomposite - adsorption study, MLR, and GA modeling. Water Air Soil Pollut 232:161. https://doi.org/10.1007/s11270-021-05070-x

Bohli T, Villaescusa I, Ouederni A (2013) Comparative study of bivalent cationic metals adsorption $\mathrm{Pb}$ (II), $\mathrm{Cd}(\mathrm{II}), \mathrm{Ni}$ (II) and $\mathrm{Cu}$ (II) on olive stones chemically activated carbon. J Chem Eng Process Technol. https://doi.org/10.4172/2157-7048.1000158

Chatterjee A, Schiewer S (2011) Biosorption of cadmium(II) ions by citrus peels in a packed bed column: effect of process parameters and comparison of different breakthrough curve models. Clean: Soil, Air, Water 39:874-881. https://doi.org/10.1002/clen.201000482 
Chuah TG, Jumasiah A, Azni I et al (2005) Rice husk as a potentially lowcost biosorbent for heavy metal and dye removal: an overview. Desalination 175:305-316. https://doi.org/10.1016/j.desal.2004.10.014

Das A, Bar N, Das SK (2020) Pb(II) adsorption from aqueous solution by nutshells, green adsorbent: adsorption studies, regeneration studies, scale-up design, its effect on biological indicator and MLR modeling. J Colloid Interface Sci 580:245-255. https://doi.org/10.1016/j.jcis.2020.07.017

Dowlatshahi S, Reza A, Torbati H, Loloei M (2014) Adsorption of copper, lead and cadmium from aqueous solutions by activated carbon prepared from saffron leaves. Environ Heal Eng Manag J 1:37-44

El-Hendawy A-NA (2009) The role of surface chemistry and solution $\mathrm{pH}$ on the removal of $\mathrm{Pb}^{2+}$ and $\mathrm{Cd}^{2+}$ ions via effective adsorbents from low-cost biomass. J Hazard Mater 167:260-267. https://doi. org/10.1016/j.jhazmat.2008.12.118

El-Sayed GO, Dessouki HA, Ibrahim SS (2010) Bio-sorption of Ni(II) and $\mathrm{Cd}(\mathrm{II})$ ions from aqueous solutions onto rice straw. Chem Sci J 9:1-11

Faisal AAH, Nassir ZS (2016) Modeling the removal of cadmium ions from aqueous solutions onto olive pips using neural network technique. Al-Khwarizmi Eng J 12:1-9

Faisal AAH, Sulaymon AH, Khaliefa QM (2018) A review of permeable reactive barrier as passive sustainable technology for groundwater remediation. Int J Environ Sci Technol 15:1123-1138. https://doi.org/10.1007/s13762-017-1466-0

Faisal AAH, Al-Wakel SFA, Assi HA et al (2020a) Waterworks sludge-filter sand permeable reactive barrier for removal of toxic lead ions from contaminated groundwater. J Water Process Eng 33:101112. https://doi.org/10.1016/j.jwpe.2019.101112

Faisal AAH, Nassir ZS, Naji LA et al (2020b) A sustainable approach to utilize olive pips for the sorption of lead ions: numerical modeling with aid of artificial neural network. Sustain Chem Pharm 15:100220. https://doi.org/10.1016/j.scp.2020.100220

Faisal AAH, Ahmed DN, Saleh B et al (2021) Elimination of hazard cadmium ions from simulated groundwater using Hydroxyapatite coated filter cake made of sewage sludge and cement kiln dust. J Polym Environ. https://doi.org/10.1007/s10924-021-02286-0

Fetter CW (1999) Contaminant hydrogeology, 2nd edn. Prentice-Hall, New Jersey

Fiol N, Villaescusa I, Martínez M et al (2006) Sorption of Pb(II), $\mathrm{Ni}(\mathrm{II}), \mathrm{Cu}$ (II) and $\mathrm{Cd}(\mathrm{II})$ from aqueous solution by olive stone waste. Sep Purif Technol 50:132-140. https://doi.org/10.1016/j. seppur.2005.11.016

Hamdaoui O, Naffrechoux E (2007) Modeling of adsorption isotherms of phenol and chlorophenols onto granular activated carbon Part II. Models with more than two parameters. J Hazard Mater 147:401-411. https://doi.org/10.1016/j.jhazmat.2007.01.023

Hansen HK, Arancibia F, Gutiérrez C (2010) Adsorption of copper onto agriculture waste materials. J Hazard Mater 180:442-448. https://doi.org/10.1016/j.jhazmat.2010.04.050

Hashim MA, Mukhopadhyay S, Sahu JN, Sengupta B (2011) Remediation technologies for heavy metal contaminated groundwater. J Environ Manage 92:2355-2388. https://doi.org/10.1016/j.jenvman.2011.06.009

Hilal NM, Ahmed IA, El-Sayed RE (2012) Activated and nonactivated date pits adsorbents for the removal of copper(II) and cadmium(II) from aqueous solutions. Int Sch Res Not 2012:1-11. https://doi. org/10.5402/2012/985853

Kabuba J, Bafubiandi AM (2013) Comparison of equilibrium study of binary system $\mathrm{Co}-\mathrm{Cu}$ ions using adsorption isotherm models and neural network. In: International Conference on Mining, Mineral Processing and Metallurgical Engineering. Johannesburg (South Africa)

Kobya M, Demirbas E, Senturk E, Ince M (2005) Adsorption of heavy metal ions from aqueous solutions by activated carbon prepared from apricot stone. Bioresour Technol 96:1518-1521. https://doi. org/10.1016/j.biortech.2004.12.005

Koldabadi SG, Ruchi V, Bhaskar KV, Lalit K (2012) Heavy metals in environment, living systems and herbal preparation: an overview. Int Res J Pharm 3:128-130
Krause P, Boyle DP, Bäse F (2005) Comparison of different efficiency criteria for hydrological model assessment. Adv Geosci 5:89-97. https://doi.org/10.5194/adgeo-5-89-2005

Marques PA, Pinheiro HM, Teixeira J, Rosa MF (1999) Removal efficiency of $\mathrm{Cu}^{2+}, \mathrm{Cd}^{2+}$ and $\mathrm{Pb}^{2+}$ by waste brewery biomass: $\mathrm{pH}$ and cation association effects. Desalination 124:137-144. https://doi. org/10.1016/S0011-9164(99)00098-3

Mujtaba Munir MA, Liu G, Yousaf B et al (2020) Synergistic effects of biochar and processed fly ash on bioavailability, transformation and accumulation of heavy metals by maize (Zea mays L.) in coalmining contaminated soil. Chemosphere 240:124845. https://doi. org/10.1016/j.chemosphere.2019.124845

Nag S, Bar N, Das SK (2019) Sustainable bioremadiation of Cd(II) in fixed bed column using green adsorbents: application of Kinetic models and GA-ANN technique. Environ Technol Innov 13:130145. https://doi.org/10.1016/j.eti.2018.11.007

Nag S, Bar N, Das SK (2020) Cr(VI) removal from aqueous solution using green adsorbents in continuous bed column: statistical and GA-ANN hybrid modelling. Chem Eng Sci 226:115904. https:// doi.org/10.1016/j.ces.2020.115904

Pandharipande SL, Deshmukh AR (2013) Artificial neural network approach for modeling of $\mathrm{Ni}(\mathrm{II})$ adsorption from aqueous solution using Aegel Marmelos fruit shell adsorbent. Int J Eng Sci Emerg Technol 4:27-36

Petrella A, Spasiano D, Acquafredda P et al (2018) Heavy metals retention ( $\mathrm{Pb}(\mathrm{II}), \mathrm{Cd}(\mathrm{II}), \mathrm{Ni}(\mathrm{II}))$ from single and multimetal solutions by natural biosorbents from the olive oil milling operations. Process Saf Environ Prot 114:79-90. https://doi.org/10.1016/j.psep.2017.12.010

Pugazhendhi A, Boovaragamoorthy GM, Ranganathan K et al (2018) New insight into effective biosorption of lead from aqueous solution using Ralstonia solanacearum: characterization and mechanism studies. J Clean Prod 174:1234-1239. https://doi.org/10. 1016/j.jclepro.2017.11.061

Quek SY, Wase DAJ, Forster CF (1998) The use of sago waste for the sorption of lead and copper. Water SA 24:251-256

Romero-González J, Walton JC, Peralta-Videa JR et al (2009) Modeling the adsorption of $\mathrm{Cr}(\mathrm{III})$ from aqueous solution onto Agave lechuguilla biomass: study of the advective and dispersive transport. J Hazard Mater 161:360-365. https://doi.org/10.1016/j. jhazmat.2008.03.102

Saka C, Şahin Ö, Küçük MM (2012) Applications on agricultural and forest waste adsorbents for the removal of lead (II) from contaminated waters. Int J Environ Sci Technol 9:379-394. https://doi. org/10.1007/s13762-012-0041-y

Samra SE, Jeragh B, El-Nokrashy AM, El-Asmy AA (2014) Biosorption of $\mathrm{Pb}^{2+}$ from natural water using date pits: a green chemistry approach. Mod Chem Appl 02:1-8. https://doi.org/10.4172/2329-6798.1000131

Sharma G, Naushad M (2020) Adsorptive removal of noxious cadmium ions from aqueous medium using activated carbon/zirconium oxide composite: isotherm and kinetic modelling. J Mol Liq 310:113025. https://doi.org/10.1016/j.molliq.2020.113025

Shaverdi G (2012) Developing a model for mass transfer in adsorption packed-bed filters. Concordia University, Montreal, Quebec, Canada

Singha B, Bar N, Das SK (2015) The use of artificial neural network (ANN) for modeling of $\mathrm{Pb}$ (II) adsorption in batch process. J Mol Liq 211:228-232. https://doi.org/10.1016/j.molliq.2015.07.002

Yang Y, Lin X, Wei B et al (2014) Evaluation of adsorption potential of bamboo biochar for metal-complex dye: equilibrium, kinetics and artificial neural network modeling. Int J Environ Sci Technol 11:1093-1100. https://doi.org/10.1007/s13762-013-0306-0

Yetilmezsoy K, Demirel S (2008) Artificial neural network (ANN) approach for modeling of $\mathrm{Pb}$ (II) adsorption from aqueous solution by Antep pistachio (Pistacia Vera L.) shells. J Hazard Mater 153:1288-1300. https://doi.org/10.1016/j.jhazmat.2007.09.092

Zheng H, Liu D, Zheng Y et al (2009) Sorption isotherm and kinetic modeling of aniline on Cr-bentonite. J Hazard Mater 167:141-147 